DOI: https://doi.org/10.47405/mjssh.v5i6.417

\begin{tabular}{|c|c|}
\hline 75 & Malaysian Journal of Social Sciences and Humanities (MJSSH) \\
\hline Malaysian Journa of & Volume 5, Issue 6, June 2020 \\
\hline (MJ - SSH) & e-ISSN : 2504-8562 \\
\hline & $\begin{array}{l}\text { Journal home page: } \\
\text { www.msocialsciences.com }\end{array}$ \\
\hline
\end{tabular}

\title{
Pengaruh Teknologi Digital Terhadap Penglibatan Pelajar dalam Aktiviti Kokurikulum Sekolah Menengah
}

\author{
Sheila Michael' ${ }^{1}$ Abdul Said Ambotang1 \\ 1Fakulti Psikologi dan Pendidikan, Universiti Malaysia Sabah (UMS) \\ Correspondence: Sheila Michael (ivyandrew@yahoo.com)
}

\begin{abstract}
Abstrak
Artikel ini mengkaji konsep pengaruh teknologi digital terhadap penglibatan pelajar dalam aktiviti kokurikulum sekolah menengah. Teknologi digital dalam kajian ini meliputi semua jenis peranti elektronik, gajet dan aplikasi yang menggunakan maklumat dalam bentuk digital termasuklah komputer riba, telefon pintar, serta lain-lain peranti berteknologi tinggi. Walaupun teknologi digital mempunyai faedah penggunaannya namun ia dikatakan memberi kesan kepada gaya hidup pelajar. Aktiviti kokurikulum kurang menjadi perhatian mereka sehingga mengabaikan kepentingannya ke atas pembentukkan dan keperibadian diri pelajar sekaligus memberi kesan ke atas perkembangan pendidikan. Oleh itu, teknologi digital didapati mempunyai pengaruh terhadap penglibatan pelajar dalam aktiviti kokurikulum sekolah menengah.
\end{abstract}

Kata kunci: teknologi digital, penglibatan pelajar, aktiviti kokurikulum, sekolah menengah

\section{The Influence of Digital Technology Towards Student Involvement in Secondary School Co-Curricular Activities}

\begin{abstract}
This article reviews the concept of digital technology influences towards student involvement in secondary school co-curricular activities. Digital technology in this study covers all types of electronic devices, gadgets and applications that use the information in digital form including laptops, smartphones, as well as other high-tech devices. Although digital technology has its own benefits, it is said to have an impact on student's lifestyle. Co-curricular activities are less concerned by ignoring the importance of students' self-determination and self-esteem, thus affecting their educational development. Therefore, digital technology is found to have influence on student involvement in secondary school co-curricular activities
\end{abstract}

Keywords: digital technology, student involment, co-curricular activities, secondary school

\section{Pengenalan}

Kokurikulum dalam pendidikan telah ditekankan sejak sekian lama oleh para sarjana. Pada zaman Renaissance, Vittoria da Feltre (1378-1446), berpendapat bahawa pendidikan tidak akan lengkap jika 
kegiatan praktikal seperti sukan dan permainan tidak termasuk dalam kurikulum sekolah. Pandangan ini dipersetujui dan diterapkan dalam pendidikan tahun demi tahun, namun bergantung kepada sejauh mana ia dilaksanakan di sekolah dengan serius. Di rantau ini, pengakap pertama sekolah ditubuhkan di Singapura pada tahun 1909. Pada masa itu, kokurikulum dianggap sebagai aktiviti luaran. Melalui pindaan Kursus Pengajian Sekolah 1956 yang digubal dalam Akta Pendidikan 1961, Kementerian Pendidikan telah menggariskan pelaksanaan kokurikulum di sekolah di mana aktiviti tersebut dinamakan sebagai aktiviti kumpulan (Ab. Alim, 2004).

Sehubungan itu, strategi dalam pelaksanaan kokurikulum yang telah diperkenalkan oleh Kementerian Pendidikan termasuklah menyeimbangkan aktiviti kokurikulum dengan pelajaran yang dijalankan di kelas melalui proses kesepaduan kurikulum dengan kokurikulum, melibatkan semua pelajar berbilang kaum dalam setiap aktiviti kokurikulum, melibatkan pelajar dan sekolah dalam khidmat masyarakat dan merancang aktiviti kokurikulum yang akan dijalankan dengan teliti. Selain itu, setiap aktiviti kokurikulum perlulah direkodkan dan dinilai secara berterusan agar penghargaan dapat diberikan kepada pelajar, guru dan pihak lain yang banyak menyumbangkan dalam menjayakan sesebuah aktiviti kokurikulum. Strategi pelaksanaan kokurikulum juga amat menitikberatkan mengenai pencapaian akademik pelajar.

Dewasa ini, peningkatan pencapaian kokurikulum di setiap sekolah semakin dititikberatkan. Pencapaian kokurikulum sekolah merangkumi kehadiran, penglibatan, pencapaian dan anugerah pelajar perlulah diambil kira bagi memastikan pencapaian kokurikulum memenuhi saranan Kementerian Pendidikan Malaysia. Malah, peruntukan markah sebanyak sepuluh peratus sebagai salah satu kriteria yang diambil kira untuk memasuki universiti menunjukkan bahawa penglibatan pelajar dalam aktiviti kokurikulum perlu diberikan perhatian. Walau bagaimanapun, terdapat banyak faktor yang mempengaruhi pencapaian pelajar melalui penglibatan kokurikulum. Pelbagai kajian telah dijalankan menjurus kepada aktiviti kokurikulum dan salah satu menjadi fokus utama adalah teknologi digital. Selain itu, ia turut meninjau penglibatan pelajar dalam aktiviti kokurikulum bagi memastikan matlamat kegiatan kokurikulum mampu dicapai seperti mana ditekankan dalam dasar pendidikan negara. Oleh itu, kajian ini akan melihat pengaruh teknologi digital terhadap penglibatan pelajar dalam aktiviti kokurikulum sekolah menengah.

\section{Teknologi Digital}

Istilah teknologi berasal daripada perkataan Yunani iaitu "techne" yang bermaksud seni atau kemahiran yang digunakan untuk menyelesaikan masalah, memperbaiki penyelesaian yang sudah ada pada suatu masalah, mencapai matlamat, mengendalikan hubungan input atau output yang diterapkan atau melakukan fungsi tertentu. Selain itu, teknologi juga adalah pembuatan, pengubahsuaian, penggunaan dan pengetahuan alat, mesin, teknik dan kaedah organisasi (Liddel, Scott, Jones \& McKenzie, 1940). Dalam erti kata lain, ia boleh merujuk kepada pengumpulan alat, termasuklah jentera, pengubahsuaian, pengaturan dan prosedur. Sejak 200 tahun yang lalu, terdapat perubahan ketara dalam istilah teknologi. Pada abad ke-20 iaitu semasa revolusi perindustrian, istilah ini telah mendapat populariti di seluruh dunia (Cradock \& Baldwin, 1833). Ini termasuklah penekanan di mana teknologi adalah tenaga yang bertindak sebagai penggerak untuk panduan atau menjalankan kehidupan kita. Ia adalah hasil daripada inovasi dan kreativiti manusia. Ia menukarkan sumber asli kepada barangan pengguna yang digunakan oleh masyarakat dan manusia. Malah, teknologi telah membawa tahap automasi ke peringkat yang tinggi sehingga menjimatkan masa dan usaha manusia. Disebabkan itu, akses kepada maklumat kini menjadi lebih mudah dan lokasi jauh pula semakin dekat. Sistem teknologi maklumat dan komunikasi telah menyediakan kemudahan sedemikian rupa sehingga dunia sekarang secara globalnya mudah dihubungi. Bagaimanapun, tidak semua teknologi digunakan untuk tujuan baik. Perkembangan senjata pemusnah secara besar-besaran telah membawa ancaman serius kepada masyarakat sepanjang sejarahnya.

Terdapat tiga gelombang dalam teknologi digital. Gelombang pertama dimulakan dengan kemunculan 
kerangka utama komputer pada tahun 1950-an. Sepanjang dekad berikut, kerangka utama komputer termasuk terminal monokrom pelbagai pengguna, telah banyak digunakan di syarikat besar. Penggunaannya, bersempena dengan format data yang standard, membolehkan pemprosesan maklumat digital dalam lingkungan rangkaian antara organisasi. Dalam gelombang pertama ini, komponen digital dimasukkan ke dalam beberapa produk tradisional seperti suis telefon. Walau bagaimanapun, biasanya komponen ini tidak dapat dilihat oleh pengguna. Oleh itu, interaksi modaliti dan pola penggunaan, sebahagian besarnya tetap sama (King \& Lyytinen, 2005; Tilson et al., 2010).

Gelombang kedua pula, dimulakan dengan kemunculan dua teknologi utama iaitu komputer peribadi dan internet. Fungsi asas komputer peribadi telah diperkenalkan pada Macintosh pertama (1984). Ia termasuk Sistem Operasi (OS) dengan Antaramuka Pengguna Bergrafik (GUI) yang dimodelkan pada 'desktop', dan tetikus sebagai peranti input yang membolehkan manipulasi secara langsung pada objek di skrin (Ehn, 1988). Komputer Macintosh yang pertama digunakan terutamanya di universiti dan organisasi kerajaan. Walau bagaimanapun, komputer peribadi yang telah diseragamkan dengan ' $M S$ Windows' tidak lama lagi muncul sebagai pilihan yang mampu dimiliki, mudah dikonfigurasikan, dan pelbagai fungsi, serta dengan cepat tersebar ke dalam bidang perniagaan dan rumah. Memandangkan 'MS Windows' membenarkan pengguna memasang dan menjalankan perisian pihak ketiga, fungsi komputer peribadi boleh dikembangkan jauh melebihi apa-apa maksud reka bentuk asal (Zittrain, 2006). Peningkatan mendadak dalam pemprosesan, kapasiti penyimpanan dan kemampuan penulisan grafik, membolehkan penciptaan dan pengeditan maklumat digital yang banyak (gambar, bunyi \& video). Sebaliknya, internet membolehkan pengguna menyebar, menerbit, mengedar dan mendapatkan maklumat melalui protokol transmisi data pakej, server klien logik dan standard HTML (Lyytinen \& Rose, 2003). Oleh kerana jaringan antara sistem operasi dan aplikasi membenarkan maklumat daripada sumber yang berbeza supaya digabungkan bersama-sama dan dipaparkan dalam perisian web, pelakon komersial tidak lama lagi memasuki jaringan internet yang akan menggunakannya sebagai platform yang standard untuk penyampaian perkhidmatan yang fleksibel (Lyytinen \& Rose, 2003). Memandangkan ia dikategorikan mengikut keterbukaan dan kawalan dikongsi (Shapiro, 1999; Kallinikos et al., 2013), internet menjadi satu set perkembangan digital yang sentiasa berubah supaya kumpulan baru boleh menggunakannya dan berdebat mengenainya pada masa akan datang (Hanseth \& Lyytinen, 2010). Bagi tujuan ini, Zittrain (2006) berhujah bahawa secara kolektif, komputer peribadi dan internet berfungsi sebagai grid generatif. Walau bagaimanapun, konsep keterbukaan dan status yang dihasilkan sebagai saluran untuk kandungan percuma (Anderson, 2009) telah dicabar oleh kebanyakan Pembekal Perkhidmatan Internet (ISP) dan pembekal perkhidmatan lain (Kourandi et al., 2014).

Seterusnya, gelombang ketiga dimulakan oleh web 2.0 - istilah 'umbrella' yang bertujuan untuk menangkap peralihan dalam reka bentuk dan penggunaan laman web (O'Reilly, 2007). Gelombang itu dimulakan oleh tiga peningkatan utama dalam teknologi web iaitu: (1) Really Simple Syndication (RSS), yang membolehkan langganan kandungan; (2) JavaScript and XML Asynchronous (AJAX), membolehkan interaksi pengguna yang lebih lancar, tanpa gangguan melalui pertukaran data yang cekap antara aplikasi web dan pelayan; (3) Application Programming Interfaces (API), yang membolehkan perkongsian kandungan antara perkhidmatan berasaskan web yang terdahulu (Cormode \& Krishnamurthy, 2008; O'Reilly, 2007). Sehingga ke tahap ini, reka bentuk laman web dominan tertumpu pada silo kandungan berkod HTML di mana pemilikan bersamaan dengan pengarang. Walau bagaimanapun, keupayaan web 2.0 mempunyai sempadan yang kabur antara pengguna dan pengeluar, dan dengan perkhidmatan yang diskret. Melalui penyebaran ciri-ciri laman web seperti ruang komen, penilaian, tag dan blog, pengguna boleh secara aktif menjana dan mencipta kandungan. Piawaian baru bermakna perkhidmatan boleh diperluaskan dengan mengintegrasikan maklumat daripada sumber luaran dan perkhidmatan novel. Sebagai contoh, apa yang disebut laman web boleh dibuat dengan hanya menggabungkan maklumat daripada sumber yang berbeza (Lessig, 2008; Cormode \& Krishnamurthy, 2008). Umumnya, kemunculan web 2.0 mengubah persepsi pengguna sebagai pencipta bersama dan aktif serta web sebagai platform yang merangkumi semua peranti dan perkhidmatan digital (O'Reilly, 2007). 


\section{Penglibatan Pelajar Dalam Aktiviti Kokurikulum Sekolah Menengah}

Kajian yang dijalankan oleh Chachra et al. (2009), menunjukkan bahawa pelajar perempuan menyedari kepentingan dalam aktiviti kokurikulum berbanding pelajar lelaki dan mempunyai penglibatan yang tinggi dalam aktiviti kokurikulum sama ada berorientasikan kejuruteraan atau bukan berorientasikan kejuruteraan. Tambahan pula, peningkatan kesedaran tentang pentingnya aktiviti kokurikulum dan penglibatan pelajar perempuan turut meningkat dalam tempoh empat tahun persekolahan mereka. Walau bagaimanapun, peningkatan masa dalam aktiviti kokurikulum berorientasikan kejuruteraan adalah tinggi di kalangan pelajar lelaki. Hasil daripada kajian tersebut juga memaparkan perbezaan yang menarik antara jantina iaitu pelajar perempuan lebih cenderung untuk mengambil peranan kepimpinan manakala pelajar lelaki lebih terlibat dalam aktiviti yang melibatkan reka bentuk atau kerja pertukangan (hands-on).

Namun begitu, Dumais (2002) mendapati bahawa perempuan mempunyai kadar penyertaan aktiviti kokurikulum berasaskan kebudayaan lebih tinggi dan menerima pulangan yang lebih baik dalam modal kebudayaan berbanding lelaki. Beliau menyatakan bahawa sosialisasi jantina dapat menggalakkan pelajar lelaki mengurangkan modal kebudayaan mereka, terutama semasa pelajar membangunkan identiti dan jantina mereka. Pelajar lelaki kadang-kadang merasakan keperluan untuk melindungi identiti mereka daripada dituduh yang mereka tidak maskulin oleh rakan-rakan (Pascoe, 2007; Morris, 2008). Ini sama dengan apa yang dipanggil para sarjana 'budaya perempuan' di mana pelajar lelaki sengaja memaparkan minat pada masa lapang dan subjek dibina sebagai lelaki maskulin (Francis, 1999) sambil mengelakkan apa-apa yang boleh mengaitkan mereka dengan kewanitaan (Warrington, Younger \& Williams, 2000).

Selain itu, terdapat kajian yang menunjukkan bahawa penyertaan pelajar perempuan dalam aktiviti kokurikulum agak ketinggalan berbanding pelajar lelaki. Penyertaan pelajar perempuan adalah dua hingga enam peratus lebih rendah berbanding lelaki (Colabianchi et al., 2012). Penyataan tersebut seiiring dengan pendapat Milosevic (1995) yang mendedahkan bahawa pelajar lelaki mengambil bahagian dalam aktiviti kokurikulum jauh lebih banyak daripada perempuan dan perbezaan ketara meningkat apabila mereka menjadi lebih berusia. Walau bagaimanapun, Darling (2015) mendakwa pelajar perempuan pada masa kini mengatasi lelaki dalam penyertaan aktiviti kokurikulum seperti seni dan kelab akademik. Sesetengah kajian mendapati bahawa corak penyertaan aktiviti kokurikulum berbeza mengikut jantina berdasarkan jenis aktiviti. Perempuan cenderung untuk memilih bilangan yang lebih besar dan kepelbagaian jenis aktiviti, manakala lelaki lebih cenderung untuk mengambil bahagian dalam organisasi sukan eksklusif (Eccles et al., 2003; Metsapelto \& Pulkkinen, 2014).

Snyder dan Spreitzer (1977) mendapati bahawa pelajar perempuan yang menyertai aktiviti kokurikulum seperti gimnastik mempunyai jangkaan pendidikan yang lebih tinggi berbanding pelajar perempuan yang menyertai bola keranjang, trek, atau tiada sukan sama sekali. Penyertaan sukan juga dikaitkan dengan peningkatan akses kepada kursus sains perempuan (Hanson \& Kraus, 1998). Namun begitu, Eitle (2005) mendapati bahawa penyertaan dalam sukan individu dan beberapa sukan berpasukan dikaitkan dengan pencapaian yang lebih tinggi dalam skor ujian untuk lelaki dan perempuan manakala permainan besbol, bola baling, bola sepak, atau bola keranjang dikaitkan secara negatif dengan skor ujian lelaki dan tiada hubungan dengan skor ujian pelajar perempuan. Sukan berpasukan didapati positif dikaitkan dengan lelaki di kolej matrikulasi, tetapi bukan perempuan (Kaufman \& Gabler, 2004).

\section{Teknologi Digital dengan Penglibatan Pelajar dalam Aktiviti Kokurikulum Sekolah Menengah}

Penggunaan teknologi digital di kalangan pelajar telah meningkat pesat sejak sedekad yang lalu. Namun begitu, timbul persoalan mengenai bagaimana masa yang dihabiskan untuk aktiviti digital dapat menjejaskan kanak-kanak dengan cara yang positif atau negatif (Putnam, 2000; Turkle, 2011; 
Bell, Bishop \& Przybylski, 2015; George \& Odgers, 2015). Pelajar yang melalui peringkat perkembangan kritikal seperti pembentukan identiti dan membina persahabatan positif, tenggelam dalam era digital (George \& Odgers, 2015). Kajian daripada Turkle (2011) berpendapat bahawa pelajar hari ini berinteraksi dengan lebih banyak lagi dengan telefon mereka antara satu sama lain, yang boleh menyebabkan mereka terlepas pengalaman sosial penting termasuklah penglibatan kokurikulum. Walau bagaimanapun, penyelidik lain mengatakan bahawa pelajar masih berinteraksi antara satu sama lain seperti sebelumnya dan mempunyai kualiti yang sama. Namun begitu, tempat untuk interaksi sosial yang telah berubah menjadi digital (Boyd, 2014). Oleh kerana persahabatan dan komunikasi dengan rakan sebaya adalah penting untuk pemkembangan kemahiran sosial sepanjang hayat, terdapat kebimbangan iaitu kemahiran sosial pelajar mungkin boleh diubah atau terjejas secara negatif apabila dibuat secara digital (George \& Odgers, 2015).

Satu kajian yang dijalankan oleh Roberts dan Foehr (2008) mengenai aktiviti kokurikulum pelajar, mencadangkan media baru seperti Facebook, Twitter dan lain-lain menggantikan atau meningkatkan aktiviti rekreasi lain tetapi tidak mengambil masa daripada pelajar. Dalam erti kata lain, mereka berpendapat bahawa masa yang dihabiskan oleh pelajar di rangkaian laman sosial adalah masa yang sama biasanya digunakan untuk aktiviti kokurikulum dan kesan daripada itu tidak mengambil masa produktif mereka untuk belajar. Walau bagaimanapun, terdapat beberapa faktor perilaku boleh mempengaruhi aktiviti fizikal di kalangan remaja. Sebagai contoh, penggunaan teknologi yang semakin meningkat telah dicadangkan sebagai penyumbang yang mungkin untuk menurunkan tahap aktiviti fizikal di kalangan komuniti global termasuk di Amerika Syarikat (Ng \& Popkin, 2012).

Walau bagaimanapun, teknologi telah dijadikan sebagai salah satu penyebab aktiviti kokurikulum menurun dan tingkah laku yang tidak aktif. Kurangnya aktiviti fizikal kerana kekerapan menonton televisyen, penggunaan komputer, dan permainan digital iaitu sepatutnya menggunakan masa tradisional untuk aktiviti fizikal. Daripada ibu bapa yang menghantar anak-anak mereka ke luar untuk bermain masa lapang kini berlaku peningkatan hiburan yang didorong oleh teknologi. Kebanyakan isi rumah di Amerika Syarikat iaitu 88 peratus kanak-kanak mempunyai permainan digital konsol seperti Sony Play Station, Microsoft Xbox, dan Nintendo Game Cube (Hersey \& Jordan, 2007). Lapan hingga lima peratus kanak-kanak juga mempunyai akses kepada komputer di rumah (Hersey \& Jordan, 2007) dan lebih daripada 90 peratus bermain permainan digital pada komputer mereka (DeBell \& Chapman, 2003). Selain itu, teknologi dalam bentuk permainan digital dan hiburan berkaitan jelas merupakan isu daripada segi menghadkan waktu harian untuk aktiviti kokurikulum. Sesetengah penyelidik menyimpulkan bahawa tahap aktiviti fizikal yang rendah di kalangan pelajar disebabkan oleh aktiviti waktu skrin yang berlebihan (teknologi seperti menonton televisyen, penggunaan komputer dan bermain permainan video). Kebanyakan kajian hipotesis perhubungan ini tidak dapat disimpulkan (Gorely, Marshall \& Biddle, 2004; Roberts et al., 2005; Ekelund et al., 2006). Walau bagaimanapun, kajian baru-baru ini di kalangan pelajar berusia 9 hingga 15 tahun menyokong hipotesis ini dan menunjukkan persamaan negatif antara aktiviti fizikal dan masa skrin (Carlson et al., 2010).

Namun begitu, kajian pada kanak-kanak berumur 4 hingga 11 tahun mendapati bahawa 37 peratus kanak-kanak mempunyai tahap keaktifan bermain yang rendah, 65 peratus mempunyai waktu skrin yang tinggi (televisyen, komputer, tablet, dan sebagainya), dan 26 peratus mempunyai kombinasi kedua-duanya (Anderson \& Whitaker, 2010). Selain itu, terdapat bukti bahawa jumlah masa pelajar menghabiskan waktu dalam peralatan teknologi dan media sosial di rumah serta sekolah telah menimbulkan kebimbangan mengenai kesan aktiviti ini terhadap kesihatan dan perkembangan mereka (Roser et al., 2016). Menurut satu kajian, berlaku peningkatan di kalangan remaja yang menghabiskan masa dalam menggunakan komputer atau telefon bimbit telah dilabel sebagai ketagih terhadap Internet. Ini didapati mengganggu rutin harian seseorang dan sering dikaitkan dengan kemurungan dan tekanan serta banyak perilaku negatif lain (Sjolie \& Thuen, 2002). 


\section{Rumusan}

Secara keseluruhannya, teknologi digital didapati mempengaruhi penglibatan pelajar dalam aktiviti kokurikulum. Maka, teknologi digital perlu diambil perhatian memandangkan ia bergantung kepada kehadiran pelajar dalam aktiviti tersebut. Sehubungan itu, kertas konsep ini diharapkan dapat dijadikan rujukan kepada semua khususnya pihak sekolah. Sumbangan kajian ini amat penting dalam menjawab persoalan kajian terutama apabila ia membuktikan wujudnya pengaruh teknologi digital terhadap penglibatan pelajar dalam aktiviti kokurikulum sekolah menengah. Walau bagaimanapun, pengkaji berharap hasil kajian ini mampu dijadikan garis panduan dalam menangani permasalahan yang wujud pada masa kini.

\section{Rujukan}

Ab. Alim, A. R. (2004). Pengurusan Gerak Kerja Kokurikulum. Selangor: Penerbit Oxford Sdn. Bhd. Anderson, C. (2009). Free: The Future of a Radical Price. London: Random House.

Anderson, S. E., \& Whitaker, R. C. (2010). Household routines and obesity in US preschool-aged children. Pediatrics, 125(3), 420-428.

Bell, V., Bishop, D. V. M. \& Przybylski, A. K. (2015). The debate over digital technology and young people. British Medical Journal, 351.

Boyd, D. (2014). It's complicated: The social lives of networked teens. New Haven, CT: Yale University Press.

Carlson, S. A., Fulton, J. E., Lee, S. M., Foley, J. T., Heitzler, C., \& Huhman, M. (2010). Influence of limit-setting and participation in physical activity on youth screen time. Pediatrics, 126(1), e89e96.

Chachra, D., Chen, H. L., Kilgore, D., \& Sheppard, S. (2009). Outside the Classroom: Gender Differences in Extracurricular Activities in Engineering Students.

Colabianchi, N., Johnston, L., \& O' Malley, P. (2012). Sports participation in secondary schools: Resources available and inequalities in participation - A BTG research brief. Ann Arbor: Bridging the Gap Program Survey Research Center, Institute for Social Research, University of Michigan.

Cormode, G., \& Krishnamurthy, B. (2008). Key Differences between Web 1.0 and Web 2.0, First Monday (13:6).

Cradock, G. \& Baldwin, C. (1833). Universal Technological Dictionary (Vol. 1).

Darling, N. (2015). Participation in extracurricular activities and adolescent adjustment: Crosssectional and longitudinal findings. Journal of Youth and Adolescence, 34(5), 493-505. $10.1007 / \mathrm{s} 10964$.

DeBell, M., Chapman, C., Kleiner, A., Lewis, L., Hudson, L., \& Shafer, L. (2003). Computer and Internet Use. Editorial Note, 5(4), 7.

Dumais, S., (2002). Cultural capital, gender, and school success: the role of habitus. Sociology of Education 75 (1), 44-68.

Ehn, P. (1988). Work-Oriented Design of Computer Artifacts. Stockholm: Arbetslivscentrum.

Eitle, T. M. (2005). Do Gender and Race Matter? Explaining the Relationship Between Sports Participation and Achievement. Sociological Spectrum 25:177-195.

Ekelund, U., Brage, S., Froberg, K., Harro, M., Anderssen, S. A., Sardinha, L. B., et al. (2006). TV viewing and physical activity are independently associated with metabolic risk in children: The European Youth Heart Study. PLoS Medicine, 2: 2449-2456.

Eccles, J. S., Barber, B. L., Stone, M., \& Hunt, J. (2003). Extracurricular activities and adolescent development. Journal of Social Issues, 59, 865-890.

Francis, B. (1999). Lads, Lasses and (New) Labour: 14-16-year-old students' responses to the 'laddish behaviour and boys' underachievement' debate. British Journal of Sociology of Education, 20(3), 355-371.

George, M. J., \& Odgers, C. L. (2015). Seven fears and the science of how mobile technologies may be influencing adolescents in the digital age. Perspectives on Psychological Science, 10:832851. 
Gorely, T., Marshall, S. J., \& Biddle, S. J. (2004). Couch kids: correlates of television viewing among youth. International Journal of Behavioral Medicine, 11(3), 152-163.

Hanseth, O., \& Lyytinen, K. (2010). "Design Theory for Dynamic Complexity in Information Infrastructures: The Case of Building Internet," Journal of Information Technology, 25(1), 1-19.

Hanson, S., \& Kraus, R. (1998). Women, sports, and science: Do female athletes have an advantage? Sociology of Education, 71, 93-110.

Hersey, J., \& Jordan, A. (2007). Reducing children's TV time to reduce the risk of childhood overweight: The children's media use study.

Kallinikos, J. (2012). Form, Function, and Matter: Crossing the Border of Materiality, in Materiality and Organizing: Social Interaction in a Technological World, P.M. Leonardi, B.A. Nardi and J. Kallinikos (eds.). Oxford: Oxford University Press, pp. 67-87.

Kaufman, J. \& Gabler, J. (2004). Cultural Capital and Extracurricular Activities of Girls and Boys in the College Attainment Process. April 2004. Poetics 32(2):145-168.

King, J. L. \& Lyytinen, K. (2005). Automotive informatics: information technology and enterprise transformation in the automobile world. In: Transforming Enterprise, Dutton, W., et al. (eds.), pp. 283-312. MIT Press, Boston, MA.

Kourandi, F., Krämer, J., \& Valletti, T. M. (2014). Net Neutrality, Exclusivity Contracts and Internet Fragmentation, Information Systems Research (Forthcoming).

Lessig, L. (2008). Remix: Making Art and Commerce Thrive in the Hybrid Economy. New York: The Penguin Press.

Liddell, H. G., Scott, R., Jones, H.S., \& McKenzie, R. (1949). A Greek and English Lexicon.

Lyytinen, K., \& Rose, G. M. (2003). The disruptive nature of information technology innovations: the case of internet computing in systems development organizations. MIS quarterly, 557-596.

Metsapelto, R. L., \& Pulkkinen, L. (2014). The benefits of extracurricular activities for socioemotional behaviour and school achievement in middle childhood: An overview of the research. Journal for Educational Research Online, 6(3), 10-33.

Milosevic, L. (Ed.). (1995). Fairplay: Gender and physical education. Leeds, UK: Leeds City Council.

Morris, E. W. (2008). 'Rednecks, 'Rutters', and 'Rithmetic': social class, masculinity, and schooling in a rural context. Gender and Society, 22, 728-751.

Ng, S. W., \& Popkin, B. M. (2012). Time use and physical activity: a shift away from movement across the globe. Obesity reviews, 13(8), 659-680.

O'Reilly, T. (2007). What is Web 2.0: Design patterns and business models for the next generation of software. Communications \& Strategies 65(1):17-37.

Pascoe, C. J. (2007). Dude, you're a fag: Masculinity and sexuality in high school. Berkeley: University of California Press.

Putnam, R. D. (2000). Bowling Alone: The Collapse and Revival of American Community. New York: Simon \& Schuster.

Roberts, D., Foehr, U., \& Rideout, V. (2005). Use of individual media. Menlo Park, CA: The Henry J. Kaiser Family Foundation.

Roberts, D. F., \& Foehr, U. G. (2008). Trends in Media Use. March 2008. The Future of Children 18(1):11-37.

Roser, K., Schoeni, A., Foerster, M., \& Roosli, M. (2016). Problematic mobile phone use of Swiss adolescents: is it linked with mental health or behaviour?. International Journal of Public Health, 61(3), 307-315.

Shapiro, A. L. (1999). The Control Revolution: How the Internet Is Putting Individuals in Charge and Changing the World We Know. New York, NY: Public Affairs.

Sjolie, A. N., \& Thuen, F. (2002). School journeys and leisure activities in rural and urban adolescents in Norway. Health Promotion International, 17(1), 21-30.

Snyder, E. E., \& Spreitzer, E. (1977). Participation in sport as related to educational expectations among high school girls. Sociology of Education, 50, 47-55.

Tilson, D., Lyytinen, K., \& Sorensen, C. (2010a). "Desperately Seeking the Infrastructure in IS Research: Conceptualization of "Digital Convergence" as Co-Evolution of Social and Technical Infrastructures," System Sciences (HICSS), 2010 43rd Hawaii International Conference on: IEEE, pp. 1-10. 
DOI: https://doi.org/10.47405/mjssh.v5i6.417

Tilson, D., Lyytinen, K., \& Sørensen, C. (2010b). "Research Commentary-Digital Infrastructures: The Missing IS Research Agenda," Information Systems Research, 21(4), 748-759.

Turkle, S. (2011). Alone Together: Why we expect more from technology and less from each other. New York: Basic Books.

Turkle, S. (2011). Life on the Screen: Identity in the Age of the Internet. Simon and Schuster.

Warrington, M., Younger M. \& Williams, J. (2000). 'Student Attitudes, Image and the Gender Gap'. British Educational Research Journal, 26(3), 393-407.

Zittrain, J., (2006). The Generative Internet. Harvard Law Review, Vol. 119, p. 1974, May 2006; Oxford Legal Studies Research Paper No. 28/2006; Berkman Center Research Publication No. $2006 / 1$. 